\title{
Appreciate it from Inside--to Overlook Chinese Traditional Aesthetics of Artist Conception in Appreciation of Early Spring
}

\author{
Luo Huajin ${ }^{1, a}$ \\ ${ }^{1}$ College of fine arts, Hunan Normal University, Yuelu District, Changsha City, Hunan Province, China \\ a905169746@qq.com
}

\begin{abstract}
According to traditional theory, painting should be the imprint of mind, which serves as a principle to both artists and the audience. Guo Xi, an ancient Master of Landscape painting, sticks to the principle by conveying his mind when drawing the outline of the landscape. Chinese traditional aesthetics behind his paintings are of vast value in future research and have exerted a far-reaching effect later. The writer has done careful study on the painting Early Spring. Coupled with related theories of traditional painting and culture, the paper is attempted to analyze Guo Xi and his painting from a more newly thought-based perspective. That means the writer tries to analyze Early Spring from Guo's view and figure out his theory of aesthetics in terms of his thought inside. From all practice above, the writer will lead you into a poetic and pictorial world ignited by spirit of painting and artist conception. Through the unique perspective provided, infinite traditional wisdom shows together with the romantic expression inclusively of China.
\end{abstract}

Keywords: Early Spring, Chinese Aesthetics, Spirit of Painting, Artist Conception

\section{“心”的重构一从郭熙《早春图》看中国造境美学 \\ 罗华锦 1, a}

1 湖南师范大学美术学院, 岳麓区, 长沙市, 湖南省, 中国

905169746@qq.com

\section{摘要}

“画乃心印”是中国传统画论中提出的对绘画之人和观画之人共同的精神要求。郭熙是北宋山水画艺术的集大成 者, 其艺术亦是从“心”发而兴于山水, 他在创作中所融入的中国传统美学思想对后世影响深远, 具有极高的研 究价值。“心”的重构是在通过对画史画论和中国传统文化思想相关文献的阅读和研究，以及长时间深入的对原 作进行临习之后，对郭熙其人、其作品和思想达到了一个新（心）的理解。这即是对《早春图》本身从个人视 角的重新解读, 亦是对郭熙美学思想从“心”的阐述。以此作为一个门径, 进入中国画诗意的可以栖居的世界, 感受其中的笔墨精神, 意境和独特的观看方式, 最终由此体会古老的中国智慧与极致浪漫的中国式表达。

关键词: 早春图，中国美学，笔墨精神，意境

\section{1.前言}

时隔十载, 我国台北故宫博物院的“镇院国宝”， 宋画的三座巨擎:《溪山行旅图》(范宽绘)、《早春图》 (郭熙绘)、《万壑松风图》(李唐绘) 于今年十月再次 同台向公众展出, 引发国内外关注。由于疫情防控原 因, 多数人无法亲临现场一睹真迹, 但丝毫不影响此 次展出成为艺术界的一大盛谈。宋代是中国历史上传 统绘画艺术发展的一座高峰, 院画繁盛, 文人画开始
兴起，不论是宫廷官贵又或是民间百姓，举国皆有绘 事与鉴藏之风。时人不仅创作了众多不朽的艺术作品 流传后世, 如今我们能见到的许多画史中记载的六朝 至宋之前的名作也多是宋代时的摹本。当权者对于文 化，对于绘画艺术的重视造就了整个社会浓厚的文艺 氛围, 也造就了一批中国绘画史上的大家，他们的艺 术成就以及对后世的影响至今仍难以逾越。恰逢近日 又临习早春, 此次再会, 更深感其中之妙趣情思, 遂 作此文。用不同于以往的视角从早春图中窥探郭熙的 
山水世界，对其造境的美学思想进行 “心” 的重构, 从而进一步体会中国传统山水绘画艺术中极具智慧 的浪漫与情怀。

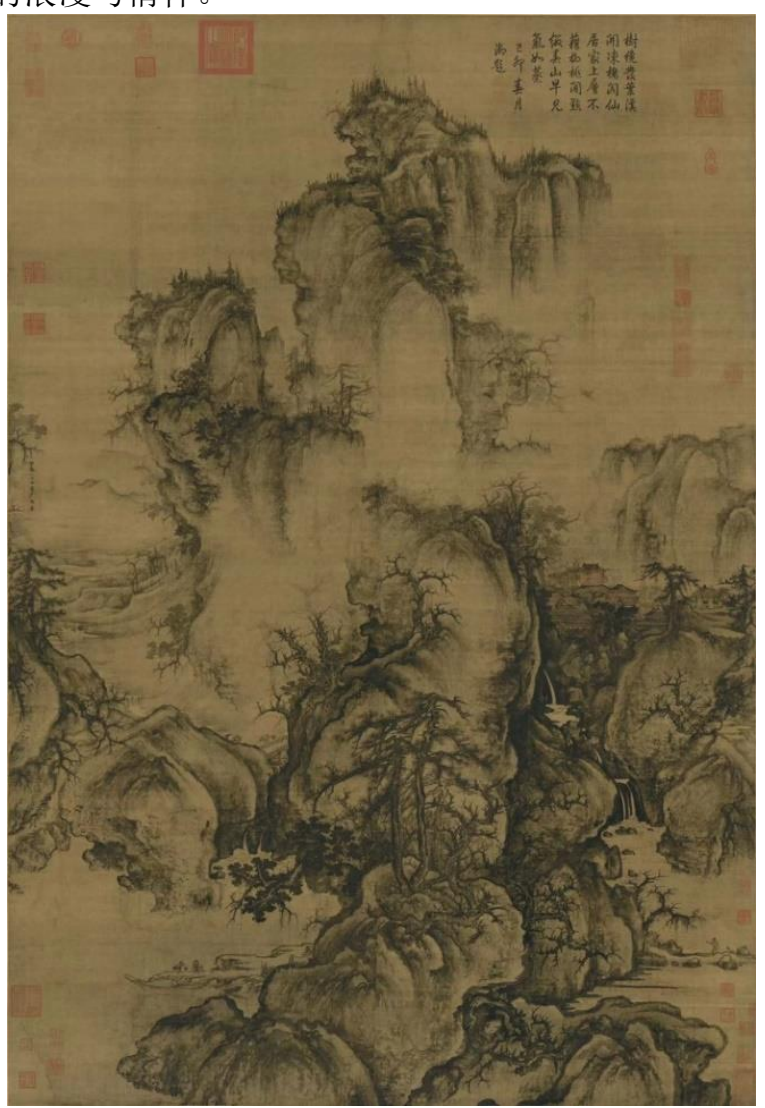

图 1 郭熙《早春图》

\section{2. 郭熙与《早春图》}

郭熙与其《早春图》说是家喻户晓或尚且不及, 但在艺界, 前后却是至少人人皆有所耳闻的中国传统 山水画“大家”与“大作”。由此便只就其人与此画略作 必要说明。

郭熙其人,生于北宋前期河阳府温县 (今属河南), 故又称“郭河阳”。早年好游于方外, 其画本无师承, 后取法李成又博采众长而成自家面貌, 颇具盛名。神 宗时入画院, 后擢为待诏直长, 尤受圣宠。其画不仅 甚为神宗皇帝所喜, 还深受当时文人名流所爱。这是 郭熙的人生中最灿烂的一段, 苍润益壮的画风已然形 成, 其体悟人生与纵情山水的美学思想也已熟稔。《早 春图》这幅不朽名作便是在这样的一个时期间 (熙宁 五年, 公元 1072 年) 创作出来的。此画用郭熙本人 创造性的视角和精到的艺术语言书写出了冬未尽, 春 未满, 万物在旭日中迷蒙着悄然复苏的景象, 故而名 为“早春”。此画是郭熙为数不多的传世真迹之一, 不 仅在画史上具有极高的地位, 对于后世研究北宋的思 想文化也具有重要的历史价值。

\section{3. 郭熙美学思想在《早春图》中的显现}

《早春图》作为郭熙绘画生涯后期风格成熟的代
表作品, 图中无疑是蕴含着其纯熟的绘画技巧, 创造 性的构思和观察方式以及他对天道、对自然、对自己 人生无尽的体悟与感怀。故而, 下文将从笔墨语言、 经营造景以及“远”的观看方式三个方面来阐述郭熙 《早春图》中所呈现的中国造境美学的思想。

\section{1. 笔墨，亦是精神}

笔墨向来被视作中国画中一个最为重要的标志 性符号。从字面上看, 笔和墨就是中国画在创作过程 中所使用的工具和材料, 但笔与墨合而言之又成了中 国画中最优美的艺术语言。随着历史不断发展至今, 笔墨又俨然成了中国绘画艺术的一种文化的象征。笔 墨的背后可以是一个个体的人格和品质, 也可以是一 个时代的审美和追求, 还可以是一个民族世代相传的 文明与精神。

郭熙的用笔, 取法于李成, 但“郭熙之于李成不仅 有继承之力, 更有再创造之功。”[1]李成用笔精微, “毫 锋颖脱”,其形状小而尖, 素有“攒针”之称。郭熙继承 了李成所创的蟹爪、卷云等笔法, 但在线条的抒写上 则较之李成更显圆润益壮, 含蓄的中锋也让笔势运动 的组合更为浑厚。至于用墨, 李成善用淡墨, 所营造 的画面平淡氮氲, 活脱秀雅, 是为一绝。而郭熙则在 掌握了精妙的淡墨运法之上“五色兼具”, 可谓层层修 饰, 耐心谋划。唐张彦远在《历代名画记》中说道“运 墨而五色具”，便是我们常说的“墨分五色”。不过这 “五色”既不是指五种颜色, 也不是单单说墨所呈现出 的黑白深浅的不同程度，而是墨这种中国特有材料的 五种不同性质及相关联的情态。他们分别是 “焦”、 “浓”、“重”、“淡”、“清”五种质态。在《早春图》之中, 郭熙自李成演变而来又具有自身气格的用笔已然具 有了圆厚遒劲的新面貌。而在用墨上则更是恰如其分 地实践了何为“运墨而五色具”, 不庈其烦, 层层叠饰, 最终让墨与笔和谐而统一。二者相互辉映, 让那高山 流水, 烟云树石呈现出了无比丰富的情态。

正是这样的笔墨, 共同组成了郭熙画面中最有意 味的形式。它们是工具, 是材料, 是技法也是语言, 还是郭熙造境美学最重要的载体。笔墨, 亦是精神, 其蕴含的意义已然超出了画面本身，成为那个时代的 一个缩影, 映射着笔墨的发展将会被即将成为中国文 艺领域主流的文人阶层发挥到极致。并且带着我们先 贤的古老智慧，使笔墨最终融入到我们的民族精神中 去，成为中华璀骤文明的一部分。那是一种与西画明 暗法截然不同的，具有深刻内涵的，蕴藏着万物万象 抑扬向背的阴阳哲理，也传递着中国文人自骨子里的 气格与品性。

\section{2. 造景，亦是造境}

不论是笔墨在绢纸上的谋划, 还是木石在真实空 间上的构建，与西方相比，中国人的“经营位置”更能 称得上是“浪漫主义”。因为中国人的经营位置, 所经 营的不仅仅是物象的位置, 还是一种心境, 所造出来 
的即是景观，亦是境界。景与境因何而不同？近代国 学大师王静安先生曾言“境非独谓景物也, 喜怒哀乐, 亦人心中之一境界。故能写真景物、真感情者, 谓之 有境界。”[2]可见独“景”真, 尚不能称之为有境界, 唯 “景”真“情”亦真，方可化景为境，谓之有境界。

“景” 可以是世上的万物万象, “情” 则是人的 所感所思。郭熙在《早春图》中所绘的有山石楼宇交 叠、有古木新枝更替、有烟云流水也有人物顾盼, 万 般物象合而为景。此景虽法于自然造化却又不完全等 同于自然，而是作者经过巧妙地安排、苦心地经营。 最终给了世人一个移步易景的世界, 在这个世界里无 处不弥散着郭熙生动之中又含蓄的无限情志, 如此之 景便已是生发成了境。让人观之仿若置身其中, 物我 相忘，情景交融。

说到境界就不得不提气韵, 景因 “气” 而化境。 “气韵生动” 乃是南朝谢赫所述 “六法” 之首要, 时 至今日仍被后世从艺者奉为圭臬。此法亦同为郭熙山 水造境之要。何为气韵? 又如何生动? 五代荆浩在意 结前人的基础上于其所著《笔法记》中提出了 “六 要” , 其中对于 “气”与 “韵” 作了如下阐释: “气 者, 心随笔运, 取象不惑; 韵者, 隐迹立形, 备仪不 俗”。 ${ }^{[3]}$ 不难看出, 荆浩对于气韵的论述是从创作者 的角度去谈的, 那对于创作者所创作的艺术作品本身, 气韵生动又是如何体现的? 世人可以在《早春图》中 找到答案。在《早春图》中, 气就是万物的生命, 山 石树木、人物楼阁、浮云流水都被郭熙赋予了生命, 于是他们便成了其中的气。而所有的 “气” 在郭熙的 世界里都不是孤立的个体。我们可以看到峰峦朝揖的 呼应，木阁交叠的情志、水云回转的交融，人与人之 间的顾盼相望, 所有的物象都在画中彼此交流, 各自 灵动又和谐一体。这般气韵又怎能不生动? 如此景象 又怎会无境界? 可谓之 “景” 真、“情” 真, 如此之 造景亦是造境也。

\section{3. 目远，亦是心远}

“远”式的空间构建是中国山水画最主要的构 图法则。魏晋时期山水画尚在萌芽, 南人宗炳便在其 《画山水序》中以 “远映” 围昆、阆于方寸之内, 是 为 “远映” 法。 ${ }^{[4]}$ 而几百年后, 郭熙在《林泉高致》 中提出的 “三远” , 则可以说是创造性地补充了前人 的 “远映” 之法, 将其详细展开并完美地实践到其具 体的山水创作之中。不论是宗炳的 “远映” 又或是郭 熙的 “三远” 都不离一个 “远” 字。可见, “远” 是 二者也是后人对中国山水画空间造境共通的主旨要 义。

中国山水之于西方风景画除了笔墨之外最大的 不同便是构图法的不同。西方风景画是从固定的视角 出发去描绘所见之景, 是画山水之真; 而中国山水画 则是从 “心” 出发, 跨越时间和空间, 把过去与现在 所见之丘筀形于胸中, 按照 “远” 式的构图法则营造 出所想之境, 不仅是画山水之真, 还是在写山水之意
气。可见对郭熙而言, “远” 这个字所代表的不仅仅 是空间物理上距离的长短, 它还包含了流动的时间和 心灵的空间。唐代释盿然有文写道: “远，非谓渺渺 望水, 查杳看山, 乃谓意中之远”。 ${ }^{[5]}$ 所谓诗中有画, 诗境亦可为画境, 释佼然之言与郭熙造境之 “远” 正 相契合。这个 “意中之远” 正是郭熙画中之 “远” 所 包含的那个心灵空间, 也是他对宗炳 “含道映物, 澄 怀味象”的体悟与实践。

在郭熙的《早春图》中，高远、深远、平远统而 为一, 这种创造性的三远兼具的中国式 “观看” 所带 给世人的不仅仅是视觉上的空间感, 还是一种可游可 居, 可与天地相往来的体验所形成的心灵境界。放眼 望去, 观画之人的思绪也随着目光在早春时节的雾气 迷蒙中跋山涉水, 伴着烟云流变左右顾盼, 直至渐行 渐远。视野之外的画面犹在延伸, 从自然接连天道, 在象外之境仍延续着生命的气韵。东晋名士陶潜写有

《饮酒》, 其中诗言: “结庐在人境, 而无车马喧。问 君何能尔? 心远地自偏。” ${ }^{[6]}$ 陶潜这种心灵的 “远” 与郭熙三远的构图法正相照应。郭熙在画中用 “三远” 所造之境正是倾注了无数诗人在面对人生中的自我, 面对山水之时 “情” 真的咏叹。由是观之, 郭熙之 “远” 是人之目远, 亦是心远。

\section{4. 郭熙美学思想成因分析}

任何一种思想的形成都并非是一蹴而就的, 而是 在思想者本人生活环境的睬化，民族文化的熏陶及个 人经历的影响等综合因素的作用下最终形成的。郭熙 的美学思想亦是如此。

艺术作为社会上层建筑中的一种意识形态, 一定 与所处时代的社会环境紧密联系。而在中国古代封建 社会的背景之下, 处于上层建筑核心的皇权政治对于 整个社会环境的影响无疑是直接而深刻, 甚至是主导 性的。

宋代的统治者们所采取的一系列举措共同形成 了一个有利于艺术发展的社会环境。首先, 是 “重文 抑武” 的国策。朝廷对于文治的重视使得当时的办学 之风大兴, 为之后文人士大夫阶层的发展壮大提供了 必要条件, 也为文人画的崛起埋下了伏笔。其次, 宋 代的历任君主不仅重视文治还崇尚艺学, 尤其是书画 艺术。宋建国之初便组建了 “翰林图画院” , 统治者 并不把画家当作普通工匠看待, 而是礼遇有加, 郭熙 就曾被宋神宗特赐 “宝花金带”。宋代画院对于当时 社会及后世整个中国绘画艺术的影响都举足轻重。可 以说两宋时期是中国历史上对于文艺最为崇尚的时 代。再者, 宋代整个的商业环境较之唐与五代都要宽 松, 商品经济繁荣, 北宋街头已经出现了以画谋生的 职业画家。由此可见，从宫廷贵族到民间文士，从文 化兴盛再到经济繁荣, 整个社会环境都对于当时艺术 的发展都起到了一个推动作用, 郭熙的艺术成就和美 学思想就是在这样的社会环境中萌发并逐渐走向成 熟。 
虽然政治在上层建筑中占有核心地位，但是包含 艺术在内的所有意识形态的发展规律都可以统摄于 哲学体系的范畴之下。中国的本土哲学思想发端于先 秦, 其中道家思想一直是被诸多学者视作是中国哲学 之滥解。

纵观中国山水画的发展, 其在魏晋时萌芽, 当时 的主流思想是追求自由解放的 “魏晋玄学”, 这是因 崇尚和研究老庄思想而形成的思潮。可见, 山水画的 形成是与道家崇尚自然, 追求逍遥自由的哲学思想密 切相关的。

道家鼻祖老子用“道法自然”来揭示宇宙万物的 运行规律, 这个自然不仅仅是我们现在所认识的自然 界, 它还是道之本性。唐代张璪有“外师造化, 中的心 源”的著名画论。根据《辞海》释义，“造化”二字即指 自然界, 也指自然界自身的运行演化, 还有命运之意。 而老子所说的作为道之本性的自然正好包涵了造化 的这三层意思。可见, 此自然便是这个世上最大的“造 化”。而张璪所说的师法造化不仅是师其形貌, 还应师 其内在蕴含的生命意趣与道理, 于此便是中得心源。 其实崇尚自然, 取法于自然的写实主义思想一直都伴 随着中国山水画艺术发展的始终。即使是后来的文人 写意山水, 诸如米氏父子, 其所绘之平淡天真也从来 都没有抛弃具体的物象, 更离不开自然的客观存在。 其艺术反而是对自然有自我独特体悟的一种创造。

常游于方外的郭熙对于师法自然有他自己的体 悟方式。他继承并丰富了张璪“外师造化, 中的心源” 的理论, 于是有了“身即山川而取之”[7]的感悟。通过 亲近自然, 用心地观察来融入山水的意境中。他用“步 步移, 面面看”的方式体会了山川四时之景, 朝暮之变 态的不同, 得出了“如此是一山而兼数十百山之意态” 的结论。在对自然进行艺术体验的同时, 郭熙还深刻 认识到了修“心”的重要性。他在《林泉高致》中将“所 养之不扩充”看作是世人执笔作画时不能“发兴”的首 要缘由。因此他游于方外, 深入自然, 浸润于风月烟 霞之中, 即是修身亦是修心。他在自然中体悟人生, 也是在体悟道。于是他以“潜德懿行”修成了一颗“林 泉之心”, 又带着这颗林泉之心造出了三远兼具的中 国式空间, 连通了目与心的距离, 形成了其自身的绘 画思想, 也是经典的中国造境美学。

\section{5. 结论}

当笔墨成为一种精神，当景象成为一种境界，当 “远”成为连通眼睛与心灵的媒介, 这便是郭熙源自于 “心”的造境美学, 也是充满古老智慧与极致浪漫的中 国式表达。

从乍暖还寒的早春中, 我们看到的不是一片风景, 而是一个可游可居的林泉佳境。早春之境虽为郭熙所 造, 但这却不是郭熙独自一人的世界, 而是能予万万 世人以“卧游”的心灵栖息之所。对于中华这样一个历 史悠远、崇尚文化、追求人生境界的民族而言, 没有 什么比体会艺术中所蕴含的优美思想更让人精神得
以满足了。那种虚旷放达, 与天地相往来的自由境界 不仅是古人, 更是当代世俗中无数为名利所直之人的 精神归宿。这也是中国传统山水画艺术的精神价值之 所在，它不仅能怡悦人之情性，让人“神飞扬”, “思浩 荡”。在不经意间便已视通万里, 跋山涉水, 成为“金 石”, “圭璋”不能仿佛之乐。更重要的是, 它不受时间 和空间的阻隔, 是今人对古人思想文化进行传承的重 要媒介。让后人能透过画面中的景与境跨越千年, 与 作者及作者的人生对话, 进而再与作者所处的时代进 行一场心灵的激荡。

北宋郭若虚言“画乃心印”，清石涛亦言“夫画者, 从于心也” ${ }^{[8]}$, 诸如此论皆是言画乃人之思想及情感的 显现，用“心”之人方能作动人之画。但换个角度去思 考, 这同样是在说, 后来人观画若要体味画中之心境 亦要用心, 不同的观者对于艺术品便会有不同的再创 造。这也警惕我们，不论做画者也好，做观者也罢， 都需要不断努力地提升自己, 如此方能进入到那个具 有更高智慧的“心”世界。

\section{REFERENCES}

[1] Lu, F. (2014) General history of Chinese landscape painting. Shanghai calligraphy and painting Publishing House, Shanghai.

[2] Wang, G. (2019) Poetic Remarks on the Human World. Sichuan literature and Art Publishing House, Chengdu.

[3] Pan, Y. (2007) Selected works of Chinese painting theories. Hunan Art Publishing House, Changsha.

[4] Yu, J. (1986) Chinese Painting Theory Series. People's Art Publishing House, Beijing.

[5] Guo, S. (2001) Selected literary theories of Chinese Dynasties: Volume 2. Shanghai Ancient Books Publishing House, Shanghai.

[6] Lu Q, proofreading and annotation. (1979) Tao Yuanming collection. Zhonghua Book Company, Beijing.

[7] Guo X. (2015) Lin Quan Gao Zhi. Jiangsu Phoenix literature and Art Publishing House, Nanjing.

[8] Pan Y. (2007) Selected Chinese painting theories of past dynasties: part two. Hunan Art Publishing House, Changsha.

[9] Xu X. (2017) Far space construction of Chinese landscape painting. Anhui Education Publishing House, Hefei.

[10] Zhu, J. (2021) "Experience Tao" theory and mental cultivation in traditional painting. Chinese literature and art review, 10:69-78. 